Non-peer reviewed EarthArXiv preprint.

Submitted for peer-review as Matters Arising in Nature Geoscience, December 2021.

\title{
No evidence for large subglacial source of mercury from the southwestern margin of
} the Greenland Ice Sheet.

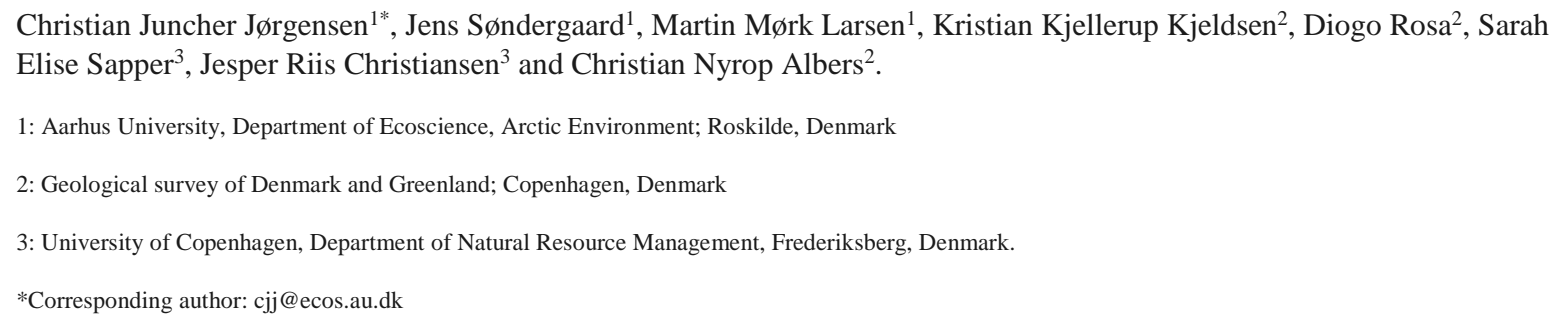

\section{Abstract}

In the current Matters Arising we present results from verifying control measurements of dissolved mercury (Hg) in glacial meltwater from the Greenland Ice Sheet (GrIS), which significantly challenges the conclusions of the recent publication by Hawkings et al. (2021) ${ }^{1}$. By direct measurements of meltwater in the same glacial catchment area, we demonstrate that the input $\mathrm{Hg}$ concentration for the regional upscaling in ${ }^{1}$ is likely vastly over-estimated with major implications for the validity of the asserted extreme yield of Hg from the GrIS. In addition, we present a plausible explanation for the high $\mathrm{Hg}$ concentration values in the study, namely hitherto unidentified cross-contamination of water samples by mercury chloride $\left(\mathrm{HgCl}_{2}\right)$, which was present and used for other purposes during field work ${ }^{2}$. Together, the result of our control study potentially invalidates the suggested implications of geologically sourced Hg under the southwestern margin of the GrIS on the Arctic ecosystem in both current and future climate conditions.

\section{Background and context}

Presence of elevated levels of dissolved mercury (Hg) in aquatic systems in Greenland is a major concern due to its potential harmful environmental and health effects. Should a hitherto undetected geological source of $\mathrm{Hg}$ exist, as suggested by ${ }^{1}$, this could have wide impacts on ecosystems with direct economic and societal consequences for Greenland, including domestic food supplies, fishery export, and challenge the potential future export sector of glacial ice and water.

$\mathrm{In}^{1}$, the geology under the GrIS is indicated as the most likely source for the elevated $\mathrm{Hg}$ concentrations in the water samples and the extreme Hg yield amounting to up to $10 \%$ of the global riverine Hg export. Significant Hg deposits are often found associated with precious metals (Ag, Au) in epithermal and Carlin-type deposits formed at shallow crustal levels ${ }^{3,4}$. However, the geology of West Greenland, in general, and of the Kangerlussuaq fjord area, in particular, is not known to host such deposit types, which could release significant quantities of Hg. This part of Greenland is dominated by Archean gneisses corresponding to deeply eroded crustal levels, which are expected to extend to underneath the ice sheet ${ }^{5,6}$.

Monitoring of $\mathrm{Hg}$ in the marine and freshwater ecosystems in Greenland has been performed over several decades in Greenland under the Arctic Monitoring and Assessment Programme 
Non-peer reviewed EarthArXiv preprint.

Submitted for peer-review as Matters Arising in Nature Geoscience, December 2021.

(AMAP), the Greenland Ecosystem Monitoring programme (GEM), and various research projects. Previous studies with direct relevance to the topic of Hawkings2021 include riverine $\mathrm{Hg}$ export from the terrestrial to the marine environment at Kobbefjord near Nuuk in West Greenland ${ }^{7}$ and Zackenberg Research Station in Northeast Greenland ${ }^{8,9}$. Results from these studies show that the baseline levels of dissolved $\mathrm{Hg}$ in riverine systems in Greenland typically range between 0.2-0.6 ng/L corresponding to $1-3 \mathrm{pM}$ dissolved $\mathrm{Hg}$, as opposed to the range of approximately 0-4000 pM (2015 data, “LG”) and 250 to 1750 pM (2018 data, “IS”, "RG”," LG”) in the proglacial river system presented by ${ }^{1}$.

\section{Summary of study design and results}

During the melt season of 2021, we conducted a control study within the same proglacial river system as ${ }^{1}$ (Figure 1). The objective of the control study was to verify if the high concentration range of dissolved $\mathrm{Hg}$ reported in ${ }^{1}$ can be reproduced.

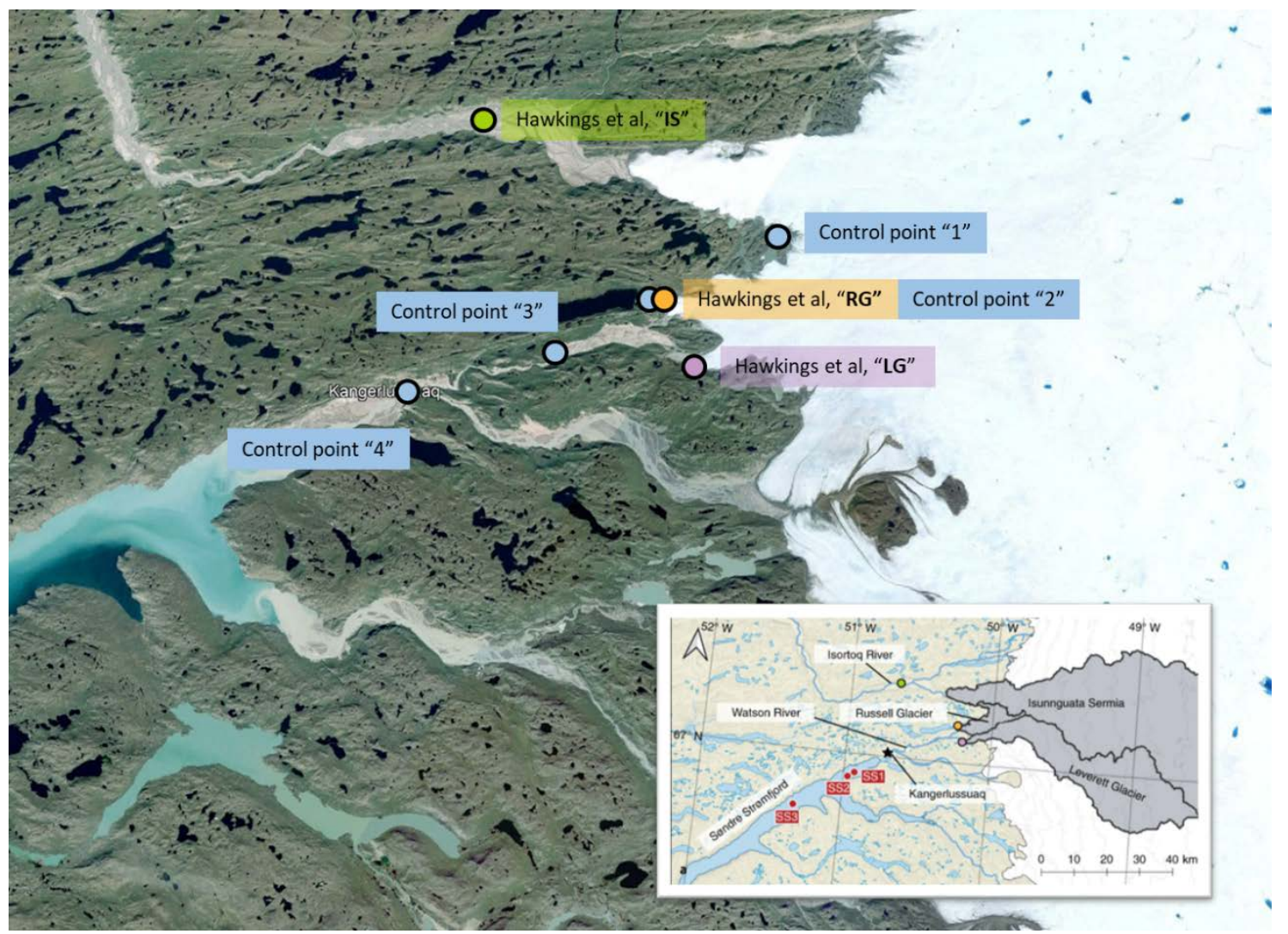

Figure 1 - Location of the four sampling stations of the control study (blue circles) near Kangerlussuaq, West Greenland together with sampling stations of Hawkings et al., 2021 (green, orange, purple). Insert panel displays meltwater catchment areas as shown in Hawkings et al., 2021. Source of base map: Google Earth, 2021.

A fundamental assumption for the control study is that, if the "extremely high $\mathrm{Hg}$ yields" found by ${ }^{1}$ is accurate and occupy potentially $10 \%$ of the global riverine $\mathrm{Hg}$ flux, the high $\mathrm{Hg}$ concentration range forming the basis for the upscaling model should be reproducible and 
Non-peer reviewed EarthArXiv preprint.

Submitted for peer-review as Matters Arising in Nature Geoscience, December 2021.

concentrations due to different mixing ratio, induced by variations between melting of snow and ice and between supra- versus subglacial meltwater routing are expected. However, the same overall concentration range of dissolved Hg should be present in the meltwater from year to year, as long as water samples are collected within the same hydrological catchment area over the active melt season.

In the control study, we simultaneously sampled meltwater using two separate sets of sampling equipment and sampling protocols. Each set of samples were then analyzed at two separate accredited laboratories in Denmark (EUROFINS and Aarhus University).

Results from the control study show that concentration levels of dissolved Hg at all four control sample stations were consistently below the analytical level of detection of $1 \mathrm{ng} \mathrm{L}^{-1}$ in all water samples $(n=8)$ analyzed at the commercial laboratory (EUROFINS). Results from the samples analyzed at Aarhus University's research laboratory confirmed these findings, with only three out of a total of 19 samples being above the AU lower limit of detection of $0.22 \mathrm{ng} \mathrm{L}^{-1}$ but lower than $1 \mathrm{ng} \mathrm{L}^{-1}$ (see table 1). Total Hg (i.e. particulate bound $\mathrm{Hg}$ ) was analyzed on a set of samples from all 4 control stations on July 29 $9^{\text {th }}$ ad August 25 2021 . Total Hg concentrations in these samples $(n=8)$ were below 1 ng $\mathrm{L}^{-1}$ (data not shown).

\begin{tabular}{|l|c|c|c|c|}
\hline Date (DOY) & $\begin{array}{c}\text { Control } \\
\text { station }\end{array}$ & $\begin{array}{c}\text { Dissolved Hg } \\
\text { (ng L-1 })\end{array}$ & Analytical laboratory & $\begin{array}{c}\text { Sampling } \\
\text { protocol }\end{array}$ \\
\hline $29-07-2021(210)$ & $1,2,3,4$ & $<1$ & Eurofins & G/E \\
\hline $29-07-2021(210)$ & $1,2,3,4$ & $<0.22$ & Aarhus University & AU \\
\hline $05-08-2021(217)$ & 4 & $<0.22$ & Aarhus University & AU \\
\hline $08-08-2021(220)$ & 4 & $<0.22$ & Aarhus University & AU \\
\hline $13-08-2021(225)$ & 4 & $<0.22$ & Aarhus University & AU \\
\hline $17-08-2021(229)$ & 4 & $<0.22$ & Aarhus University & AU \\
\hline $20-08-2021(232)$ & 4 & $<0.22$ & Aarhus University & AU \\
\hline $23-08-2021(235)$ & 4 & $<0.22$ & Aarhus University & AU \\
\hline $25-08-2021(237)$ & $1,2,3,4$ & $<1$ & Eurofins & G/E \\
\hline $25-08-2021(237)$ & $1,2,3,4^{*}$ & $<0.22$ & Aarhus University & AU \\
\hline $27-08-2021(239)$ & $4 * *$ & 0.5 & Aarhus University & AU \\
\hline $27-08-2021(239)$ & $4 * *$ & 0.4 & Aarhus University & AU \\
\hline $11-10-2021(284)$ & 2 & 0.3 & Aarhus University & AU \\
\hline $12-10-2021(285)$ & 1 & $<0.22$ & Aarhus University & AU \\
\hline $13-10-2021(286)$ & 3 & $<0.22$ & Aarhus University & AU \\
\hline
\end{tabular}

Table 1: Dissolved Hg concentrations in meltwater samples from control stations 1, 2, 3 and 4. *sample from control station 4 lost during transportation. ** Control point 4 sampled twice on the $27^{\text {th }}$ August 2021 (09:00 and 18:45).

A fundamental requirement for the extrapolations made in ${ }^{1}$ is a widespread occurrence of $\mathrm{Hg}$ in Southwestern Greenland. In addition to samples collected in the Kangerlussuaq proglacial rivers, we sampled six rivers carrying glacial meltwater in Southwest Greenland in late June and again in early September 2021 (Extended Data Fig. 1). Similar to the samples from the 
Non-peer reviewed EarthArXiv preprint.

Submitted for peer-review as Matters Arising in Nature Geoscience, December 2021.

Kangerlussuaq area, all samples from these six sites were below the detection limit of $1 \mathrm{ng} \mathrm{\textrm {L } ^ { - }}$ ${ }^{1}$ total Hg.

\section{Discussion}

In contrast to the extremely high Hg concentrations in the proglacial river system presented $\mathrm{in}^{1}$, the results from the control samples show concentration levels of dissolved $\mathrm{Hg}$ within the same low order of magnitude as typically found in riverine environments in Greenland ${ }^{7-9}$ and other Arctic rivers ${ }^{10-13}$.

One of the differences between ${ }^{1}$ and the control study is the part of the melt season in which the majority of the sampling is performed. Where meltwater sampling of ${ }^{1}$ was performed during seasonal increase in meltwater discharge (day of year (DOY) 135-210 in 2015 and DOY 171-197 in 2018), the control study was conducted during seasonal decrease in meltwater discharge (DOY 210-286). This difference in seasonality may produce some variability in dissolved $\mathrm{Hg}$ as the mixing ratio between sub- and supraglacial meltwater will vary over the season. However, since the dissolved $\mathrm{Hg}$ is postulated to originate from a subglacial bedrock and thus be carried from the source to the proglacial rivers by subglacial meltwater, the signal of elevated Hg concentrations should also be measurable during the part of the season where the ratio between melting of snow and ice and routing of the meltwater is different. Since the control study clearly shows that this is not the case, an alternative explanation for the presence of dissolved $\mathrm{Hg}$ in the water samples of ${ }^{1}$ must be investigated.

A major differences between ${ }^{1}$ and the control study lies in the potential presence and use of $\mathrm{HgCl}_{2}$ for sample preservation during field work. While not directly mentioned in the manuscript or included in the list of references of ${ }^{1}$, the discharge curve presented in Figure 3c in ${ }^{1}$, was first published in Figure 2 of a study performed by the same research consortia ${ }^{2}$. Collection of water samples for both studies were thus performed by the same research consortia in 2015 and 2018. An important methodological aspect mentioned in ${ }^{2}$, but omitted by ${ }^{1}$, is the presence and use of mercuric chloride $\left(\mathrm{HgCl}_{2}\right)$ to 'poison' and preserve water samples for later analysis of dissolved methane $\left(\mathrm{CH}_{4}\right)$ in meltwater (see also similar approach $i^{14}$ ) during the field work of at least 2015.

$\mathrm{In}^{2}$, it is described that each sample was poisoned with $24 \mathrm{mg} \mathrm{HgCl}_{2}$, equal to $93 \mu$ mole $\mathrm{Hg}$. By rough estimation, the absolute amount of $\mathrm{Hg}$ added to a single field sample following this approach would take dilution of $47000 \mathrm{~L}$ water to reach a Hg concentration of $2000 \mathrm{pM}$. This calculation demonstrates that only trace amounts of $\mathrm{HgCl}_{2}$ are needed to accidentally pollute pristine water samples to the level reported in ${ }^{1}$ and that extreme care should take when sampling and storing environmental samples for $\mathrm{Hg}$ analysis if at the same time using $\mathrm{HgCl}_{2}$ for preservation in other samples during the same field campaign.

Instead of being of geological origin, we find it possible that the Hg present in the glacial meltwater samples in ${ }^{1}$ is a product of one or more of the following sources of error: 1 ) accidental direct injection of $\mathrm{HgCl}_{2}$ into the samples following sampling; 2) cross- 
Non-peer reviewed EarthArXiv preprint.

Submitted for peer-review as Matters Arising in Nature Geoscience, December 2021.

contamination of water samples by gaseous $\mathrm{Hg}$ volatized from $\mathrm{HgCl}_{2}$ during long-term storage of water samples in close proximity to concentrated $\mathrm{HgCl}_{2}$ stock solutions or the intentionally contaminated samples of ${ }^{2}$ or; 3 ) usage of $\mathrm{Hg}$ polluted sampling equipment or similar source of contamination linked to the presence and use of $\mathrm{HgCl}_{2}$ in the field camp and/or in the analytical laboratory.

\section{Conclusion}

Control samples of dissolved Hg sampled in 2021 within the same hydrological catchment area cannot reproduce the extremely elevated Hg concentration levels of 2015 and 2018 reported by Hawkings et. al. ${ }^{1}$ By contrast, the concentration levels of dissolved Hg in the control study was consistently below $1 \mathrm{ng} \mathrm{L}^{-1}$. Instead, the extremely elevated riverine $\mathrm{Hg}$ concentrations of ${ }^{1}$ could be due to accidental sample contamination by the presence of mercuric chloride used for other purposes. A logical consequence of the lack of reproducibility in concentration levels of dissolved $\mathrm{Hg}$ is that the main conclusion of ${ }^{1}$ concerning the magnitude of Hg yield from the Greenland Ice Sheet and potential consequences for the public health and environment is most likely erroneous.

\section{Extended Data}

Sampling stations near Kangerlussuaq: Two independent sets of water samples ("Set 1" and “Set 2”) collected at four unique sampling stations (Control point “1”,"2”,"3”, and “4”) were sampled on 29/07/2021 and 25/08/2021. A single set of samples were collected at all four stations on 12/10/2021. Furthermore, single samples were collected at Control point " 4 " on 5, 8, 13, 15, 17, 20, 21 and 27 August 2021 to indicate temporal variability.

Control point " 1 " is located at the sample location of ${ }^{14,15}$, which represent a minor glacial outlet of the Isunnguata Sermia glacier. Control point " 2 " is identical to station "RG" of 1 , representing glacial runoff from Russel Glacier and the upstream environment. Control point "3" is located downstream of the confluence point of the meltwater rivers draining Russel Glacier and Leverett Glacier (station "LG" in ${ }^{1}$ ). Control point "4" is located the river bend immediately upstream of the Watson River bridge in Kangerlussuaq, representing the combined meltwater input from Russel, Leverett and Isorlersuup glaciers.

By nature of design, each control point represents an incrementally increasing catchment area of glacial discharge from the Greenland Ice Sheet. By increasing the catchment area and mixing of water from different sources, annual variations in bed connectivity due to varying development of the subglacial drainage channel network should be cancelled out.

Sampling and analytical protocol - GEUS/Eurofins (G/E): Water was sampled in $30 \mathrm{~mL}$ acidwashed Amber glass vials with gas-tight Teflon-lined screw lids. For each sampling point and time, water was sampled twice: One sample was taken by lowering a vial well below the surface, shaking with the lid on, emptying and refilling to $90 \%$ of the volume of the vial (non-filtered sample). A second vial was filled by passing water through a $0.45 \mu \mathrm{m}$ filter (Qmax PES membrane filter, Frisenette, Denmark) using a syringe that was thoroughly rinsed in the river. The first few $\mathrm{mL}$ of the filtrate were discarded. Both vials were immediately 
closed and stored cold and in the dark until arrival at the commercial laboratory (Eurofins Denmark) within two weeks of the sampling date. Upon arrival to the laboratory, hydrochloric acid was added to the vial and within another 7 days, the sample was analysed by Cold Vapor Atomic Fluorescence Spectrometry (US EPA, 2005).

Sampling and analytical protocol - Aarhus University (AU): Discrete meltwater samples were sampled in $250 \mathrm{ml}$ glass bottles with Teflon lids before analysis. To obtain the water sample, the rinsed bottle was fully submerged until full and capped underwater to avoid any air bubbles in the bottle. Samples were kept cool and dark until analysis in the laboratory.

Water samples were analysed for THg following the US-EPA Method 1631, Revision E (USEPA, 2002). A drop of $\mathrm{BrCl}$ solution is added to the water sample to oxidise the $\mathrm{Hg}$ species to Hg. The surplus of oxidants is removed by a drop of hydroxyl/ammonium, after which $\mathrm{Hg}^{2+}$ is reduced by a $\mathrm{SnCl}_{2}$ solution and the released $\mathrm{Hg}(\mathrm{g})$ is driven by an Argon air current to a gold trap, where $\mathrm{Hg}$ is pre-concentrated. After collection for a pre-set time, the $\mathrm{Hg}$ is thermally desorbed into the atomic fluorescence detector (P.S. Analytical Millennium Merlin, Kent, UK). Detection limits, calculated as three times the standard deviations on blind samples, are typically $0.1-0.2 \mathrm{ng} \mathrm{L}$.

The accredited method is validated by participation in the QUASIMEME proficiency testing program, bi-yearly analyzing 3 unknown samples in the range 1 to $50 \mathrm{ng} / \mathrm{l}$, and using certified reference material BCR579 to ensure correct measurements.

At all sampling occasions following both sampling protocols, samples were obtained from the bank of a free-flowing and well-mixed part of the meltwater stream. Fresh gloves were worn during sampling.

Additional sampling stations: Using only the G/E sampling protocol, filtered and non-filtered water was sampled and analysed from six additional meltwater rivers in South-West Greenland. Two river received meltwater primarily from the ice sheet, while meltwater at the four remaining rivers originate from local glaciers and ice caps. The rivers are located between the towns of Nuuk and Paamiut (Extended Fig. 1.) and were sampled twice (late June and early September). 


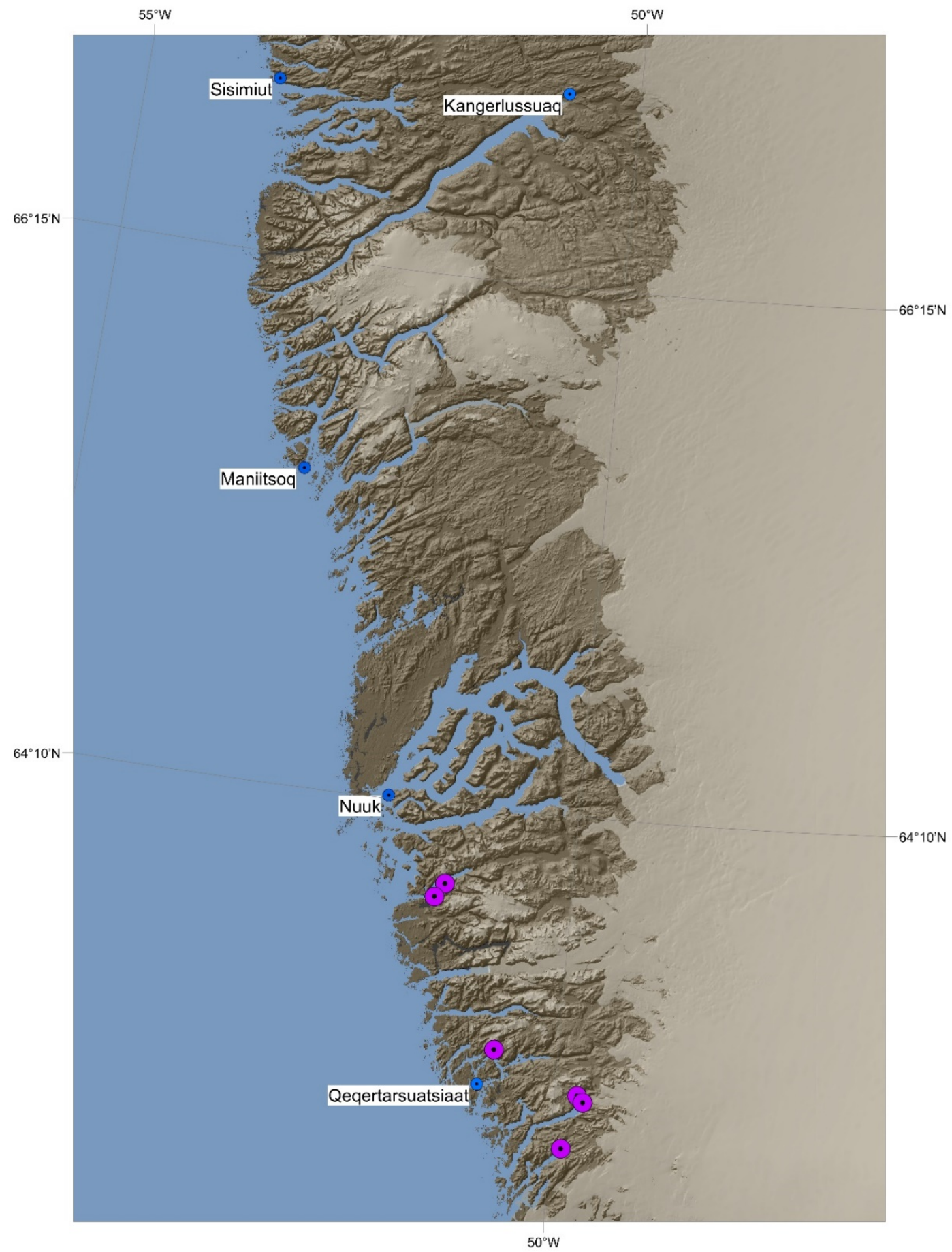

Extended Fig. 1. Location of the six additional rivers in South-West Greenland (purple circles). The two southernmost rivers receive meltwater directly from the ice sheet, while the four other rivers receives meltwater originating from local glaciers and ice caps. 
Non-peer reviewed EarthArXiv preprint.

Submitted for peer-review as Matters Arising in Nature Geoscience, December 2021.

\section{Bibliography}

1. Hawkings, J. R. et al. Large subglacial source of mercury from the southwestern margin of the Greenland Ice Sheet. Nat. Geosci. 14, 496-502 (2021).

2. Lamarche-Gagnon, G. et al. Greenland melt drives continuous export of methane from its bed. Nature 73-77 (2018). doi:10.1038/s41586-018-0800-0

3. Hofstra, A. H. \& Cline, J. Characteristics and Models for Carlin-Type Gold Deposits. in SEG Reviews 163-220 (2000). doi:10.5382/rev.13.05

4. John, D. A. et al. Descriptive Models for Epithermal Gold-Silver Deposits. U.S. Geological Survey Scientific Investigations Report 2010-5070-Q (2010).

5. Connelly, J. N. \& Mengel, F. C. Evolution of Archean components in the Paleoproterozoic Nagssugtoqidian orogen, West Greenland. Bull. Geol. Soc. Am. 112, 747-763 (2000).

6. Engström, J. \& Klint, K. E. S. Continental collision structures and post-orogenic geological history of the kangerlussuaq area in the southern part of the nagssugtoqidian orogen, central west Greenland. Geosci. 4, 316-334 (2014).

7. Rigét, F. et al. Mercury (Hg) transport in a high arctic river in northeast Greenland. Water. Air. Soil Pollut. 222, 233-242 (2011).

8. Søndergaard, J. et al. Mercury exports from a High-Arctic river basin in Northeast Greenland $\left(74^{\circ} \mathrm{N}\right)$ largely controlled by glacial lake outburst floods. Sci. Total Environ. 514, 83-91 (2015).

9. Søndergaard, J., Rigét, F., Tamstorf, M. P. \& Larsen, M. M. Mercury transport in a lowarctic river in Kobbefjord, West Greenland (64 N). Water. Air. Soil Pollut. 223, 43334342 (2012).

10. Coquery, M., Cossa, D. \& Martin, J. M. The distribution of dissolved and particulate mercury in three Siberian estuaries and adjacent Arctic coastal waters. Water, Air, Soil Pollut. 1995801 80, 653-664 (1995).

11. Emmerton, C. A. et al. Mercury export to the Arctic Ocean from the Mackenzie River, Canada. Environ. Sci. Technol. 47, 7644-7654 (2013).

12. Outridge, P. M., Macdonald, E. R. W., Wang, G. F., Stern, G. A. \& Dastoor, A. P. A mass balance inventory of mercury in the Arctic Ocean. Environ. Chem 5, 89-111 (2008).

13. Sukhenko, S. A., Papina, T. S. \& Pozdnjakov, S. R. Transport of mercury by the Katun river, West Siberia. Hydrobiol. 19922281 228, 23-28 (1992).

14. Christiansen, J. R., Röckmann, T., Popa, M. E., Sapart, C. J. \& Jørgensen, C. J. Carbon emissions from the edge of the Greenland Ice sheet reveal subglacial processes of methane and carbon dioxide turnover. J. Geophys. Res. Biogeosciences 1-13 (2021). doi:10.1029/2021jg006308 
Non-peer reviewed EarthArXiv preprint.

Submitted for peer-review as Matters Arising in Nature Geoscience, December 2021.

15. Christiansen, J. R. \& Jørgensen, C. J. First observation of direct methane emission to the atmosphere from the subglacial domain of the Greenland Ice Sheet. Sci. Rep. 8, 16623 (2018).

\section{Author contributions}

C.J.J., J.S., C.N.A., K.K.K. designed the control study. S.E.S., C.J.J., J.R.C., C.N.A. collected field samples. M.M.L. analyzed water samples at Aarhus University. D.R. performed the geological assessment. C.J.J. and C.N.A. wrote the manuscript with significant contributions from all co-authors.

\section{Competing interests.}

The authors declare no competing interests. 